\title{
Thresholds for warming-induced growth decline at elevational tree line in the Yukon Territory, Canada
}

\author{
Rosanne D. D’Arrigo, ${ }^{1}$ Robert K. Kaufmann, ${ }^{2}$ Nicole Davi, ${ }^{1}$ Gordon C. Jacoby, ${ }^{1}$ \\ Cheryl Laskowski, ${ }^{2}$ Ranga B. Myneni, ${ }^{3}$ and Paolo Cherubini ${ }^{4}$ \\ Received 1 March 2004; revised 21 June 2004; accepted 13 July 2004; published 24 September 2004.
}

[1] A few tree ring studies indicate recent growth declines at northern latitudes. The precise causes are not well understood. Here we identify a temperature threshold for decline in a tree ring record from a well-established temperature-sensitive site at elevational tree line in northwestern Canada. The positive ring width/temperature relationship has weakened such that a pre-1965 linear model systematically overpredicts tree ring widths from 1965 to 1999. A nonlinear model shows an inverted U-shaped relationship between this chronology and summer temperatures, with an optimal JulyAugust average temperature of $11.3^{\circ} \mathrm{C}$ based on a nearby station. This optimal value has been consistently exceeded since the 1960s, and the concurrent decline demonstrates that even at tree line, trees can be negatively affected when temperatures warm beyond a physiological threshold. If warming continues without significant gains in effective precipitation, the large-scale greening of recent decades could be replaced by large-scale browning. Such browning could slow or reverse carbon uptake by northern

forests. INDEX TERMS: 1615 Global Change: Biogeochemical processes (4805); 1851 Hydrology: Plant ecology; 3344 Meteorology and Atmospheric Dynamics: Paleoclimatology; 4221 Oceanography: General:

Dendrochronology; KEYWORDS: temperature, threshold, tree rings

Citation: D’Arrigo, R. D., R. K. Kaufmann, N. Davi, G. C. Jacoby, C. Laskowski, R. B. Myneni, and P. Cherubini (2004), Thresholds for warming-induced growth decline at elevational tree line in the Yukon Territory, Canada, Global Biogeochem. Cycles, 18, GB3021, doi:10.1029/2004GB002249.

\section{Introduction}

[2] Scientists use satellite sensors to track the amount of photosynthetic pigment at ground level with the normalized difference vegetation index (NDVI). NDVI data for the Northern Hemisphere indicate that the date at which this index breaches a preestablished level has come earlier in the year and that the yearly maximum value for NDVI has increased between 1981 and 1999. These results are interpreted to indicate that spring has come earlier and that summer greenness has increased [Myneni et al., 1997; Zhou et al., 2001]. The suggestion of a general "greening" by high-latitude forests is not universal. Satellite images also identify extended areas in northern North America and Russia where the vegetation has become less green: so-called "browning." Such browning is also indicated by a reduction in tree ring

\footnotetext{
${ }^{1}$ Tree-Ring Laboratory, Lamont-Doherty Earth Observatory, Palisades, New York, USA.

${ }^{2}$ Center for Energy and Environmental Studies, Boston University, Boston, Massachusetts, USA. USA.

${ }^{3}$ Department of Geography, Boston University, Boston, Massachusetts,

${ }^{4}$ Forest Ecosystems and Ecological Risks, Swiss Federal Institute for Forest, Snow and Landscape Research, Birmensdorf, Switzerland.

Copyright 2004 by the American Geophysical Union. 0886-6236/04/2004GB002249
}

width and/or density at some northern sites [e.g., Jacoby and D'Arrigo, 1995; Briffa et al., 1998; Vaganov et al., 1999; Barber et al., 2000].

[3] The presence of such extended areas of browning requires examination and further explanation. Several mechanisms have been suggested for different areas, including fire, insect infestation, and temperature-induced drought stress [e.g., Zhou et al., 2003]. Here we investigate the effects of climate by estimating the relationship between an average of monthly mean temperatures and tree rings at Twisted Tree-Heartrot Hill (TTHH), an elevational tree line site in the Yukon Territory, Canada. We chose TTHH for this case study because it is a well-established temperaturesensitive site, where the data for ring width (including raw measurements as well as standardized indices) show decline since the 1960s despite a concurrent rise in Arctic temperature [Chapman and Walsh, 1993; Hansen et al., 1999]. At nearby Dawson, Yukon Territory (see section 2), temperature has increased along with the Arctic warming (see Figure 4), while precipitation has not changed significantly. These observations suggest that persistent higher temperatures may have induced a stress on the trees. The stress may be due to temperatures rising above an optimum level for growth at this site. Above a certain level, net photosynthesis declines as the effects of thermally increasing respiration overcome the diminishing response of photosynthesis to temperature increases [Kramer and Kozlowski, 1979]. 


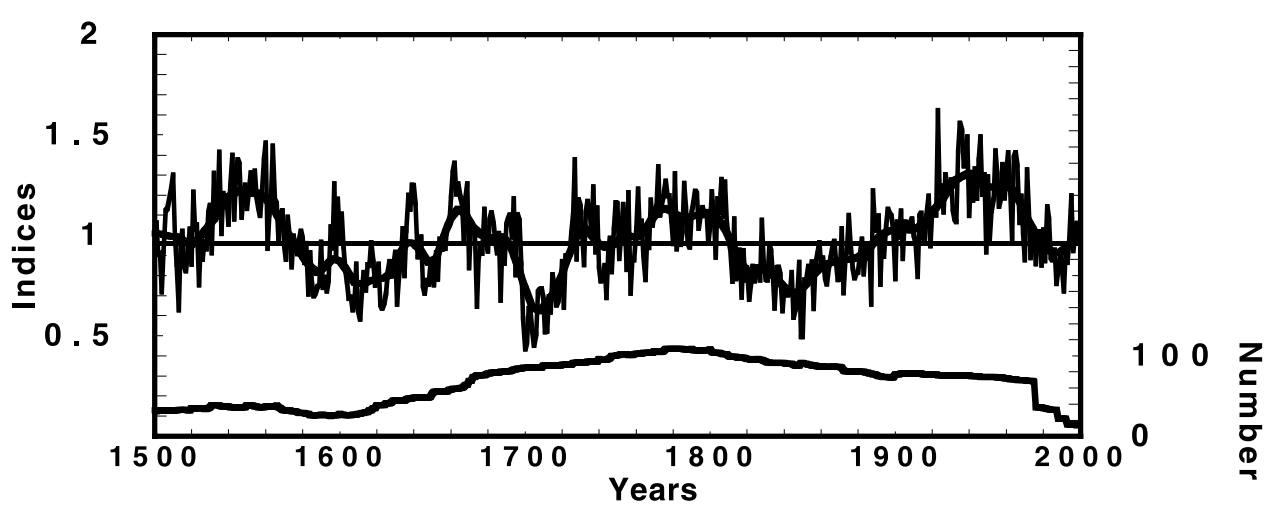

Figure 1. TTHH tree ring width chronology. Thin black line on top indicates time series from A.D. 1500 to 1999; thick black line on top shows decadally smoothed values. Bottom black line is changing sample size per year. Note growth decline in recent decades. In 1965 there are 67 core samples, decreasing to 32 in 1977 and 10 in 1998.

Also, enhanced evapotranspiration and temperature-induced drought stress could be partly responsible for the measured ring width decline at TTHH. In this paper we test the hypothesis that temperature has exceeded a critical threshold and caused TTHH ring widths to decline using both dendrochronological analyses [Cook and Kairiukstis, 1990] and nontraditional cointegration techniques [e.g., Engle and Granger, 1987].

\section{Data}

[4] The trees at the TTHH site $\left(65^{\circ} 20^{\prime} \mathrm{N}, 138^{\circ} 20^{\prime} \mathrm{W}\right.$, $1230 \mathrm{~m}$ ) are white spruce (Picea glauca [Moench] Voss), a dominant North American tree line species. Trees from TTHH were used previously to develop a 426-year ring width chronology (Jacoby and Cook [1981], A.D. 15501975 , based on samples collected in the summer of 1976). Recently, collections of living and subfossil wood (collected in the summer of 2000) were used to update and extend this record (Figure 1). During recent visits we did not find any evidence of fire, spruce bark beetle infestation, or other disturbance which might help account for the growth decline. The tree ring samples were processed using traditional methods of dating, verification of dating using the COFECHA program [Holmes, 1983], and standardization using the ARSTAN program (we use the standard chronology version [Cook and Kairiukstis, 1990]).

[5] We estimate the relationship between TTHH tree rings and temperature using meteorological data from Dawson, Yukon Territory $(324 \mathrm{~m})$, the closest station with a long record (1900 to present). These data are the adjusted version obtained from the Global Historical Climatology Network (volume 2) of the National Climatic Data Center [Vose et al., 1992], which conducted extensive quality control and corrections related to homogeneity issues and other adjustments (see Figure 3 caption). Dawson is $\sim 125 \mathrm{~km}$ south of TTHH and $\sim 900 \mathrm{~m}$ lower and is separated from the site by the Ogilvie Mountain range. A statistically significant, positive response [Fritts, 1976] to Dawson summer temperatures was found by Jacoby and Cook [1981]. Lowfrequency trends at TTHH are consistent with those ob- served in tree ring records from other elevational as well as latitudinal tree line sites which, along with the TTHH record, were used to reconstruct Northern Hemisphere and Arctic temperatures [Jacoby and D'Arrigo, 1989; D'Arrigo and Jacoby, 1993].

\section{Statistical Methodology and Results}

[6] To begin with, traditional ordinary least squares (OLS) is used to estimate a linear relationship between the tree ring and climate data. Analysis of the TTHH chronology with Dawson temperatures reveals a shift from predominantly positive correlations between 1901 and 1964 to predominantly negative correlations between 1965 and 1999 (Figure 2). This division is based on visual inspection and iterative trials of the tree data with temperature. The strongest associations are primarily in the prior and current spring and summer months. To evaluate the change from positive to negative correlations, we estimate a linear model for the tree ring/temperature relationship with data from 1900 to 1964 and use the regression coefficients to forecast ring widths for 1965-1999. Results indicate that the linear relationship with temperature systematically overpredicts the recent ring width values observed at TTHH (Figure 3). This systematic error implies that there has been a shift in the positive relationship between tree rings and temperature and/or that other factors have influenced tree growth at this site since the 1960s.

[7] The persistent difference between observed and predicted ring widths in recent decades (Figure 3) implies that the relationship between tree rings and temperature has become negative. To test the hypothesis that the sign of the relationship between tree rings and temperature has changed because temperature now exceeds a threshold, we specify a quadratic model, the simplest nonlinear model that allows the relationship between temperature and tree rings to change sign. The quadratic model is given by equation (1):

$$
\mathrm{TR}_{t}=\alpha+\beta_{1} T_{t}+\beta_{2} T_{t}^{2}+\mu_{t},
$$




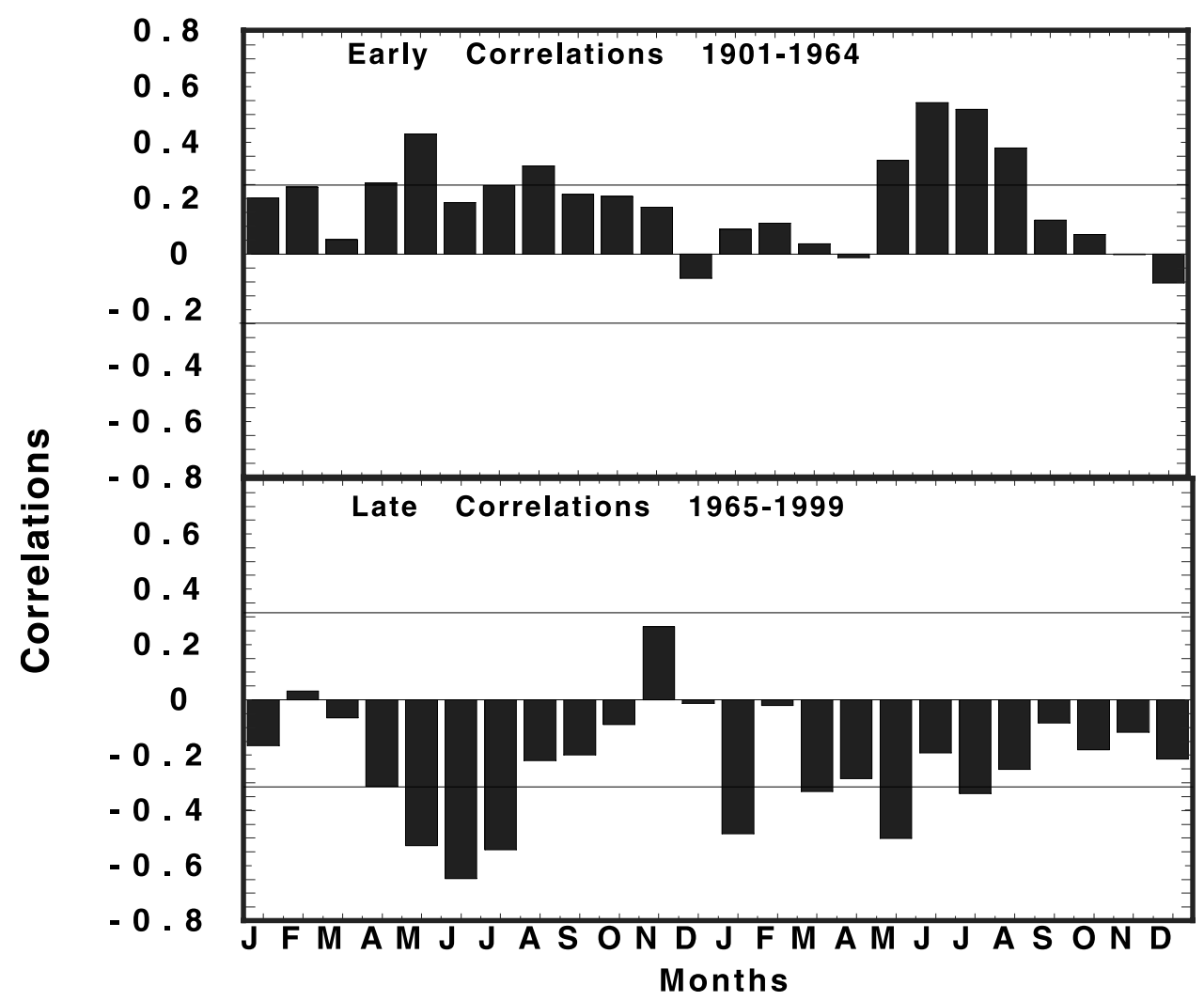

Figure 2. Correlations of TTHH ring width chronology with monthly Dawson temperatures. Relationships computed for early (1901-1964, top) and late (1965-1999, bottom) sample periods, showing shift from positive to negative correlation with temperature in both prior and current years of growth, are illustrated. Tree growth, particularly in conifers, can respond to environmental conditions in previous years [e.g., Fritts, 1976]. At TTHH the magnitude and sign of these correlations appears largely driven by low-frequency variability and change, as indicated by the relative lack of high-frequency agreement in Figure 3. Confidence limits of $95 \%$ are shown as horizontal lines.

in which TR is the tree ring index at time $t$, and $T$ is mean monthly temperature (e.g., mean July temperature). Equation (1) is consistent with the notion of a physiological optimum for tree growth, i.e., that the maximum growth rate occurs at an intermediate temperature. As noted above, the concept of an optimum temperature for tree growth is implied by the temperature curves that are used to evaluate photosynthesis, respiration, and net photosynthesis [Fritts, 1976; Kramer and Kozlowski, 1979; Tranquillini, 1979]. A physiological optimum is consistent with a positive value for $\left(\beta_{1}\right)$ and a negative value for $\left(\beta_{2}\right)$. Under these conditions the turning point associated with temperature (i.e., the growth optimum) can be calculated by setting the partial derivative of equation (1) with respect to temperature to zero and solving for temperature. Following this procedure, the turning point is given by $-\beta_{1} / 2 \beta_{2}$. As temperature increases beyond this turning point, further warming reduces ring width. Equation (1) does not impose an inverted $U$ shape on the tree ring/temperature relationship. Four other relationships (positive, negative,
U shaped, no relationship) are possible depending on the sign and statistical significance of $\beta_{1}$ and $\beta_{2}$.

[8] Estimating the relationship between temperature and tree rings is complicated by the presence of stochastic trends in these time series. The augmented Dickey Fuller (ADF) statistic [Dickey and Fuller, 1979] indicates that the TTHH chronology (1900-1999) contains a stochastic trend (that is, it is nonstationary: ADF statistic with constant and trend is $-2.51, p>0.32$ ). Stochastic trends are also present in the temperature time series for July (ADF statistic with constant and trend is $-3.25, p>0.08$ ) and August (ADF statistic with constant and trend is $-2.97, p>0.14)$ temperatures. The ADF statistics reject the null hypothesis for the other 10 monthly temperature series, which indicates that these time series for temperature may be stationary. However, there are limits to the accuracy of the ADF statistics. Most importantly, a high noise to signal ratio increases the likelihood that the ADF will reject the null hypothesis [Schwert, 1989].

[9] The identification of stochastic trends is important because using OLS to estimate the relationship between 


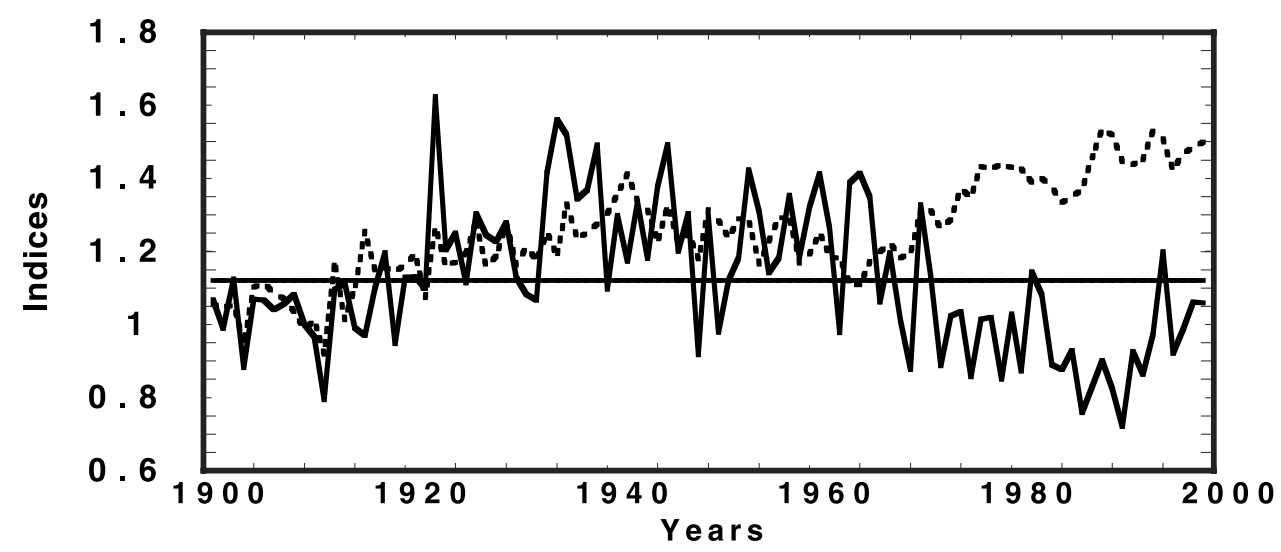

Figure 3. Results of a linear relationship between temperature and tree rings. Actual (solid line) tree ring width indices for TTHH chronology are shown. Estimates (dashed line) based on using Dawson temperatures as predictors over 1901-1964 period are shown. (These temperatures are based on adjusted data from Vose et al. [1992]. Use of adjusted data was recommended by D. Easterling (Scientific Services Division, National Oceanic and Atmospheric Administration's National Climatic Data Center) and L. Vincent (Canadian Meteorological Service) (personal communication, 2004).) Horizontal line is tree ring index mean over 1901-1999. Variance accounted for by linear regression model is 33\% $\left(\mathrm{ar}^{2}\right)$, adjusted for degrees of freedom. Model is based on temperature variables: Year $t-1$ is April, May, July, and August; year $t$ is May-August. Note that regression estimates for 1965-1999 overpredict ring width values. Analyses using unadjusted data indicated some differences relative to those reported herein (with less of a disparity between actual and estimated tree growth) but the same overall conclusion: i.e., that radial growth at this site is overpredicted by the linear model based on temperature.

variables that contain a stochastic trend may indicate a significant relationship where none exists [Granger and Newbold, 1974]. For an illustration of this effect, see Kaufmann and Stock [2003]. For this application a spurious regression may make it appear as if there is a relationship between tree rings and temperature when no relationship is present.

[10] To avoid spurious regressions, we use the notion of cointegration [Engle and Granger, 1987]. Cointegration states that if two or more series containing stochastic trends have a functionally dependent relationship, the stochastic trend present in some of the series also will be present in the others. This shared trend implies that there is at least one linear combination of the series that is stationary. Under these conditions, there will be no stochastic trend in the residuals, and the variables are said to cointegrate.

[11] To determine whether the TTHH tree rings cointegrate with temperature, we again use the ADF test, in this case to determine whether the regression residual from equation (1) is stationary. If $(\mu)$ is stationary, this would imply that temperature and tree rings cointegrate. The presence of cointegration signals that there is a statistically meaningful, long-run relationship between temperature and ring width.

[12] The notion of cointegration can be used to narrow the list of monthly temperature time series that can be used as independent variables in equation (1). Because the TTHH ring width series contains a stochastic trend (and because tree rings have an autocorrelation coefficient that is less than unity), this trend, for the purpose of the application used herein, can only be imparted by a monthly temperature series that contains the same stochastic trend. That is, a truly stationary time series for temperature cannot generate a stochastic trend in the tree ring data. On the basis of this notion we check for cointegration between ring widths and an average of temperature for July and August, the only months which have a stochastic trend that can "cointegrate" with the stochastic trend in tree rings (this narrow definition herein does not preclude our previous observations that these and other tree ring records can integrate low-frequency trends related to annual or other temperatures [e.g., Jacoby and D'Arrigo, 1989]). For example, Figure 2 shows that June has the highest simple correlations with the ring width indices (1900-1964). The ADF statistics indicate that the ring width indices cointegrate with the linear and squared values of the July-August average temperature (ADF with a constant but no trend is -4.99 ; $p<0.001)$. Together, these results indicate that there is a statistically meaningful long-run relationship between TTHH ring widths and temperature for July and August. [13] The presence of stochastic trends changes the estimation technique that is needed to estimate the relationship between ring widths and temperature. Even though the temperature and tree ring variables cointegrate, the OLS estimate of equation (1) will contain a small sample bias, and the limiting distribution will be nonnormal with a nonzero mean [Stock, 1987]. To avoid these difficulties, we estimate equation (1) using the dynamic ordinary least squares estimator (DOLS) [Stock and Watson, 1993]. DOLS generates asymptotically efficient estimates of the relation- 
Table 1. Regression Results for Equations (2) and (3) ${ }^{\mathrm{a}}$

\begin{tabular}{lc}
\hline & July-August \\
\hline Equation (2) & \\
$\beta_{1}$ & $82.18^{\mathrm{b}}[12.25]$ \\
$\beta_{2}$ & $-0.363^{\mathrm{b}}[0.054]$ \\
ADF & $-4.99^{\mathrm{b}}$ \\
Turning point $\left(-\beta_{1} / 2 \beta_{2}\right)$ & $11.3^{\mathrm{c}}$ \\
Adjusted $R^{2}$ & 0.40 \\
Equation $(3)$ & \\
$\alpha$ & $-0.70^{\mathrm{b}}(0.153)$ \\
Adjusted $R^{2}$ & 0.58 \\
\hline
\end{tabular}

${ }^{\mathrm{a}} \mathrm{ADF}$ tests on the residual from equation (1) include a constant but no time trend. Significance level of the ADF statistic is calculated using the approximation described by MacKinnon [1994]. Numbers in brackets are standard errors that are calculated using the method developed by Newey and West [1987]. Numbers in parentheses are standard errors that are estimated using ordinary least squares.

${ }^{\mathrm{b}}$ Test statistic rejects the null hypothesis at the $1 \%$ level.

${ }^{\mathrm{c}}$ Temperature is measured in tenths of a degree, so a turning point of 113 corresponds to $11.3^{\circ}$.

ship between ring widths and temperature using the following specification:

$$
\mathrm{TR}_{t}=\beta_{0}+\beta_{1} T_{t}+\beta_{2} T_{t}^{2}+\sum_{i=-s}^{s} \phi_{i} \Delta T_{t-i}+\sum_{i=-s}^{s} \pi_{i} \Delta T_{t-i}^{2}+\mu_{t},
$$

in which $\beta_{1}$ and $\beta_{2}$ represent the long-run relationship between tree rings and temperature and the $\phi$ and $\pi$ are "nuisance" parameters. The number of lags and leads $(s)$ used by the DOLS estimator is chosen with the Bayesian information criterion [Schwartz, 1978]. The maximum number of lags examined (5) is given by $N^{1 / 3}$, where $N$ is the number of observations (101). A more detailed description of how the DOLS estimator can be used to estimate the relationship among physical variables is given by Kaufmann and Stock [2003].

[14] The DOLS estimate for the relationship between ring widths and the July-August average temperature indicates that $\beta_{1}$ is statistically significant and positive while $\beta_{2}$ is statistically significant and negative (Table 1). Together, these coefficients indicate that there is an inverted U-shaped relationship between ring widths and July-August average temperature. The optimal value for this monthly average is $11.3^{\circ} \mathrm{C}$. The $95 \%$ confidence intervals associated with this optimal value is $7.0^{\circ}-$ $17.6^{\circ} \mathrm{C}$. These intervals are calculated by running Monte Carlo simulations in which the $\beta_{1}$ and $\beta_{2}$ are changed by the product of their standard errors and a normally distributed random variable (mean value zero, standard deviation 1), and the altered values of $\beta_{1}$ and $\beta_{2}$ were used to calculate the turning points. This process was repeated 1000 times, and the turning points were ranked from largest to smallest. The $95 \%$ confidence interval represents values at position 25 and 975 .

[15] Monthly Dawson temperatures above $11.3^{\circ} \mathrm{C}$ thus have a negative effect on ring width (elevational differences between Dawson and the TTHH site imply that summer temperatures could be $\sim 3.5^{\circ} \mathrm{C}$ lower at the tree site [Jacoby and Cook, 1981]). In recent decades the average JulyAugust Dawson temperature has been well above its optimal value (Figure 4). Although there are also years prior to 1965 during which this threshold is exceeded, the post1965 pattern is unique because observed temperatures consistently exceed this threshold. Obviously, these are monthly means, and the actual daily maxima will usually exceed these values.

[16] The DOLS procedure generates efficient estimates for the long-run equilibrium relationship among variables. Ring width does not adjust instantly to the equilibrium value implied by the long-run effect of temperature,

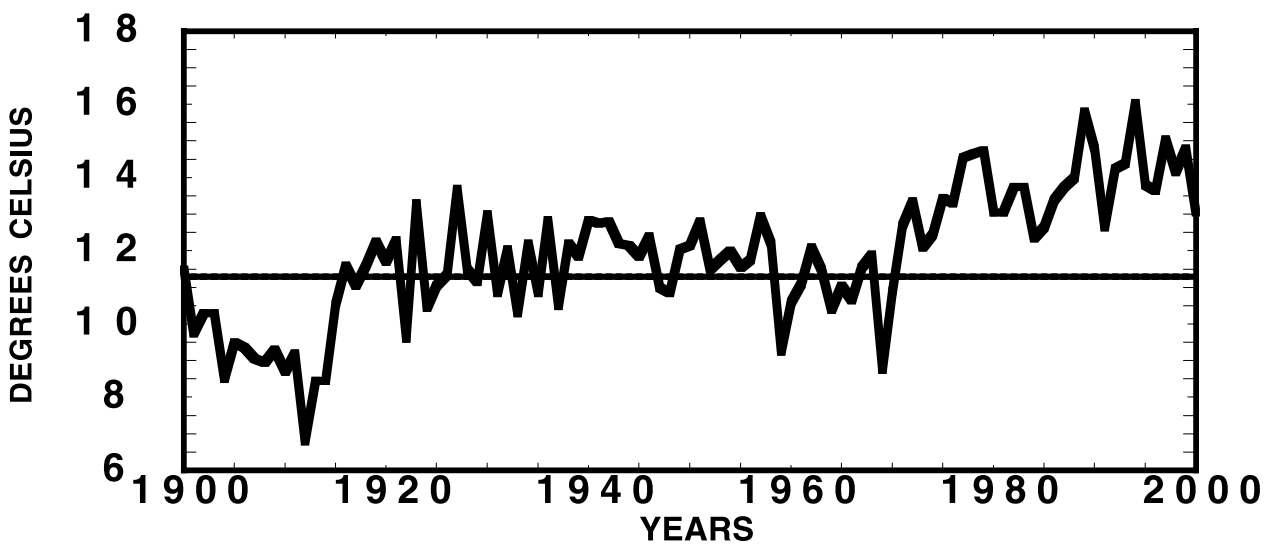

Figure 4. Comparison of observed July-August averaged temperature values (thick line) with physiological optima (straight thin line) computed for TTHH site. Because there are relatively few years in which observed temperature exceeds the threshold prior to 1965 , the correlation between ring width and temperature is generally positive (Figure 2). As noted in text, elevational differences between Dawson and the TTHH site imply that summer temperatures could be $\sim 3.5^{\circ} \mathrm{C}$ lower at the tree site [Jacoby and Cook, 1981]. 
which is given by the DOLS estimate for $\beta_{1}$ and $\beta_{2}$. To quantify the rate at which tree rings adjust to temperature, we estimate an error correction model (ECM) which is given by equation (3):

$$
\begin{aligned}
\Delta \mathrm{TR}_{t}= & \beta_{0}+\alpha \mu_{t-1}+\sum_{i=1}^{s} \theta_{i} \Delta \mathrm{TR}_{t-i}+\sum_{i=1}^{s} \psi_{i} \Delta T_{t-i} \\
& +\sum_{i=1}^{s} \gamma_{i} \Delta T_{t-i}^{2}+\sum_{j=1}^{10} \sum_{i=1}^{s} \theta_{j i} \mathrm{ST}_{j t-i}^{2}+\varepsilon_{t},
\end{aligned}
$$

in which ST are the ten stationary monthly temperature time series (ten months, January to June, September to December) of the growth year $t$, and $\mu_{t}$ is the residual from equation (2). The ECM given by equation (3) can be estimated using OLS because all the variables are stationary. By definition, the first difference of the variables that contain a stochastic trend is stationary. The finding of cointegration implies that the residual from equation (2) is stationary.

[17] The short-run dynamics at which ring width adjusts to temperature are given by the value of $\alpha$ in equation (3). The value of $\alpha$ in equation (3) indicates that fraction of disequilibrium between the equilibrium value for ring width and the previous year's observed value for ring width that is eliminated each year. The estimated value of $\alpha$ is 0.70 (Table 1). This result implies that $\sim 70 \%$ of the disequilibrium between ring width and July-August average temperature is eliminated annually. The statistically significant value of $\alpha$ also indicates that temperature Granger causes ring width [Granger, 1969]. The presence of "Granger causality" implies a statistical causal ordering. As such, the relationship between temperature and ring width extends beyond simple correlation. However, the presence of Granger causality does not necessarily imply a physically causal mechanism between temperature and ring width.

\section{Discussion and Conclusions}

[18] Our results indicate that the tree growth decline at TTHH is consistent with increases in the average JulyAugust temperature over its optimal value (Figure 4). Unlike the systematic error in the linear model (Figure 3), which highlights its lack of cointegration (ADF with constant and no time trend is $-2.25, p>0.38$ ), cointegration implies that there is no systematic error in the quadratic model. The lack of a systematic error suggests that higher July-August temperatures (beyond the trees' physiological optima) are consistent with the growth decline at TTHH after 1965.

[19] These results, combined with those for the ECM, suggest a mechanism for the quadratic relationship between ring width and July-August temperature. Early in the growing season, soil moisture can be sufficient for growth even at somewhat higher temperatures. For example, the coefficient associated with June temperature in equation (3) is positive. As summer progresses, soil moisture usually dwindles. The lack of moisture is especially stressful at high temperatures. Without a persistent increase in precipitation (the precipitation time series are stationary), the persistent increase in temperature over time beyond the $11.3^{\circ} \mathrm{C}$ threshold has a negative effect on ring width. Toward the end of the growing season when soil moisture probably is near the growing season low, the lagged values in the ECM generally have a negative effect on ring width. This would indicate that warm temperatures have a negative effect on ring width in the absence of sufficient soil moisture.

[20] Interestingly, there is cointegration with Dawson temperature in other months of the year when we truncate the TTHH series prior to the recent decline, indicating that these (nongrowing season) temperatures have also been very important in contributing to low-frequency trends at TTHH, at least until recently. Consistent with this interpretation, many of the coefficients associated with the stationary temperature series (January to June, September to December) in equation (3) are statistically significant. This is also the case when the truncated chronology is compared to the temperature record for the Northern Hemisphere, which was reconstructed using this and other tree ring records [Jacoby and D'Arrigo, 1989; D'Arrigo and Jacoby, 1993].

[21] Temperature-induced moisture stress has been used to explain recent decline and loss of positive temperature sensitivity for some latitudinal tree line and other sites in Alaska [Jacoby and D'Arrigo, 1995; Barber et al., 2000], whereas wetter sites tend to show less decline [Lloyd and Fastie, 2002]. Higher ultraviolet blue (UVB) levels [Briffa et al., 1998] delayed snowmelt [Vaganov et al., 1999], changes in respiration, and varying trends in maximum and minimum temperatures [Wilson and Luckman, 2002] also have been suggested as causes for these phenomena in some northern forests. Tree age also may be a factor in determining climate response [Szeicz and MacDonald, 1994]. Not all of these studies emphasize tree line locations. Our study indicates that trees at even the most temperaturesensitive tree line sites can show warming-induced decline. Our statistical estimates for the physiological optima are site-specific and are determined, in part, by local moisture availability. Annual Dawson precipitation does not have a stochastic trend (ADF with constant and time trend is $-5.35, p<0.001)$. This indicates that there has been no long-term increase in available moisture over the sample period. Modeling studies indicate that without increased precipitation, increases in temperature and evapotranspiration will limit net primary productivity of white spruce [Keyser et al., 2000].

[22] The recent shifts in the growth response at TTHH and other locations [e.g., Wilmking et al., 2004] may portend significant changes in northern forests. Although, as noted, satellite images indicate a general elongation of the growing season and increased summer greenness over recent decades, these data also identify areas where vegetation has browned [Myneni et al., 1997, 2001; Zhou et al., 2001, 2003]. Many of these browning regions have experienced some of the most pronounced warming on the globe [Hansen et al., 1999; Myneni et al., 2001; Zhou et al., 2001], and NDVI in these locations are negatively correlated with temperature [Zhou et al., 2003]. Should warming continue without a substantial increase in available soil moisture, the positive effects of warming [e.g., Briffa et 
al., 1995; D'Arrigo et al., 2001a] could be reversed in large areas of northern forests. The large-scale "browning" of northern forests could reduce or reverse their ability to sequester carbon [Tans et al., 1990]. Testing this hypothesis using tree rings, NDVI, and other biospheric indicators [Keeling et al., 1996; D'Arrigo et al., 2001b; Kaufmann et al., 2004] will require further investigation.

[23] Acknowledgments. This research was funded by the National Science Foundation's Ecological Rates of Change and Earth System History programs. This research was supported by the Office of Science (BER), U.S. Department of Energy, through the Western Regional Center of the National Institute for Global Environmental Change under cooperative agreements DE-FC03-90ER61010 and DE-FC02-03ER63613. We thank E. Cook and R. Wilson for advice. We gratefully acknowledge Environment Canada and Parks Canada. LDEO contribution 6633.

\section{References}

Barber, V., G. Juday, and B. Finney (2000), Reduced growth of Alaska white spruce in the twentieth century from temperature-induced drought stress, Nature, 405, 668-672.

Briffa, K., P. Jones, F. Schweingruber, S. Shiyatov, and E. Cook (1995), Unusual 20th century summer warmth in a 1000-year temperature record from Siberia, Nature, 393, 450-455.

Briffa, K., F. Schweingruber, P. Jones, and T. Osborn (1998), Reduced sensitivity of recent tree growth to temperature at high northern latitudes, Nature, 391, 678-682.

Chapman, W., and J. Walsh (1993), Recent variations of sea ice and air temperature in high latitudes, Bull. Am. Meteorol. Soc., 74, 33-47.

Cook, E., and L. Kairiukstis (Eds.) (1990), Methods of Dendrochronology: Applications in the Environmental Science, Kluwer Acad., Norwell, Mass.

D'Arrigo, R., and G. Jacoby (1993), Secular trends in high northern-latitude temperature reconstructions based on tree rings, Clim. Change, 25, $163-$ 177.

D’Arrigo, R., G. Jacoby, D. Frank, N. Pederson, E. Cook, B. Buckley, B. Nachin, R. Mijiddorj, and C. Dugarjav (2001a), 1738 years of Mongolian temperature variability inferred from a tree ring record of Siberian pine, Geophys. Res. Lett., 28, 543-546.

D'Arrigo, R., C. Malmstrom, G. Jacoby, S. Los, and D. Bunker (2001b), Correlations between maximum latewood density of annual tree rings and NDVI based estimates of forest productivity, Int. J. Remote Sens., 21 , $2329-2336$.

Dickey, D. A., and W. A. Fuller (1979), Distribution of the estimators for autoregressive time series with a unit root, J. Am. Stat. Assoc., 7, 427-431.

Engle, R. F., and C. W. J. Granger (1987), Co-integration and error correction: Representation, estimation, and testing, Econometrica, 55, 251276.

Fritts, H. (1976), Tree Rings and Climate, Academic, San Diego, Calif.

Granger, C. W. J. (1969), Investigating causal relations by econometric models and cross spectral models, Econometrica, 37, 424-438.

Granger, C. W. J., and P. Newbold (1974), Spurious regressions in econometrics, J. Econometrics, 2, 111-120.

Hansen, J., R. Ruedy, J. Glascoe, and M. Sato (1999), GISS analysis of surface temperature change, J. Geophys. Res., 104, 30,997-31,022.

Holmes, R. (1983), Computer-assisted quality control in tree-ring dating and measurement, Tree-Ring Bull., 43, 69-75.

Jacoby, G., and E. Cook (1981), Past temperature variations inferred from a 400-year tree-ring chronology from Yukon Territory, Canada, Arct. Alp. Res., 13, 409-418.

Jacoby, G., and R. D'Arrigo (1989), Reconstructed Northern Hemisphere annual temperature since 1671 based on high-latitude tree-ring data from North America, Clim. Change, 14, 39-59.

Jacoby, G., and R. D'Arrigo (1995), Tree ring width and density evidence of climatic and potential forest change in Alaska, Global Biogeochem. Cycles, 9, 227-234.

Kaufmann, R. K., and J. H. Stock (2003), Testing hypotheses about mechanisms for the unknown carbon sink: A time series analysis, Global Biogeochem. Cycles, 17(2), 1072, doi:10.1029/2002GB001962.

Kaufmann, R. K., R. D’Arrigo, L. Laskowski, R. Myneni, L. Zhou, and N. Davi (2004), The effect of growing season and summer greenness on northern forests, Geophys. Res. Lett., 31, L09205, doi:10.1029/ 2004GL019608.
Keeling, C., J. Chin, and T. Whorf (1996), Increased activity of northern vegetation inferred from atmospheric $\mathrm{CO}_{2}$ measurements, Nature, 382, $146-149$.

Keyser, A., J. Kimball, R. Nemani, and S. Running (2000), Simulating the effects of climate change on the carbon balance of North American highlatitude forests, Global Change Biol., 6, 185-195.

Kramer, P., and T. Kozlowski (1979), Physiology of Woody Plants, Academic, San Diego, Calif.

Lloyd, A., and C. Fastie (2002), Spatial and temporal variability in the growth and climate response of treeline trees in Alaska, Clim. Change, $52,481-509$

MacKinnon, J. (1994), Approximate asymptotic distribution functions for unit-root and cointegration tests, J. Bus. Econ. Stat., 12, 167-176.

Myneni, R., C. Keeling, C. Tucker, G. Asrar, and R. Nemani (1997), Increased plant growth in the northern latitudes from 1981 to 1991, Nature, 386, 698-702.

Myneni, R., J. Dong, C. Tucker, R. Kaufmann, P. Kauppi, J. Liski, L. Zhou, V. Alexeyev, and M. Hughes (2001), A large carbon sink in the woody biomass of northern forests, Proc. Natl. Acad. Sci. U. S. A., 98, 14,78414,789 .

Newey, W. K., and K. D. West (1987), A simple positive semi-definite heteroskedasticity and autocorrelation consistent covariance matrix, Econometrica, 55, 703-708.

Schwartz, G. (1978), Estimating the dimension of a model, Ann. Stat., 6, $461-464$.

Schwert, G. W. (1989), Tests for unit roots: A Monte Carlo investigation, J. Bus. Econ. Stat., 7, 147-159.

Stock, J. H. (1987), Asymptotic properties of least squares estimators of cointegrating vectors, Econometrica, 55, 1035-1056.

Stock, J. H., and M. W. Watson (1993), A simple estimator of cointegrating vectors in higher-order integrated systems, Econometrica, 61, 783-820.

Szeicz, J., and G. MacDonald (1994), Age-dependent tree-ring growth responses of subarctic white spruce to climate, Can. J. For. Res., 24, $120-132$.

Tans, P., I. Fung, and T. Takahashi (1990), Observation constraints on the global atmospheric $\mathrm{CO}_{2}$ budget, Science, 247, 1431-1438.

Tranquillini, W. (1979), Physiological Ecology of the Alpine Timberline, Springer-Verlag, New York.

Vaganov, E., M. Hughes, A. Kirdyanov, F. Schweingruber, and P. Silkin (1999), Influence of snowfall and melt timing on tree growth in subarctic Eurasia, Nature, 400, 149-151.

Vose, R., R. Schmoyer, P. Steurer, T. Peterson, R. Heim, T. Karl, and J. Eischeid (1992), The Global Historical Climatology Network: Longterm monthly temperature, precipitation, sea level pressure, and station pressure data, Rep. NDP-041, Carbon Dioxide Inf. Anal. Cent., Oak Ridge Natl. Lab., Oak Ridge, Tenn.

Wilmking, M., G. Juday, B. Barber, and H. Zald (2004), Recent climate warming forces contrasting growth responses of white spruce at treeline in Alaska through temperature thresholds, Global Change Biol., in press.

Wilson, R., and B. Luckman (2002), Tree-ring reconstruction of maximum and minimum temperatures and the diurnal temperature range in British Columbia, Canada, Dendrochronologia, 20, 1-12.

Zhou, L., C. Tucker, R. Kaufmann, D. Slayback, N. Shabanovi, and R. Myneni (2001), Variations in northern vegetation activity inferred from satellite data of vegetation index during 1981 to $1999, J$. Geophys. Res., 106, 20,069-20,083.

Zhou, L., R. Kaufmann, Y. Tian, R. Myneni, and C. Tucker (2003), Relation between interannual variations in satellite measures of northern forest greenness and climate between 1982 and 1999, J. Geophys. Res. 108(D1), 4004, doi:10.1029/2002JD002510.

P. Cherubini, Forest Ecosystems and Ecological Risks, Swiss Federal Institute for Forest, Snow and Landscape Research, CH-8903, Birmensdorf, Switzerland

R. D. D'Arrigo, N. Davi, and G. C. Jacoby, Tree-Ring Laboratory, Lamont-Doherty Earth Observatory, Columbia University, P.O. Box 1000, RT 9W, Palisades, NY 10964, USA. (rdd@1deo.columbia.edu; ndavi@ 1deo.columbia.edu; druid@1deo.columbia.edu)

R. K. Kaufmann and C. Laskowski, Center for Energy and Environmental Studies, Boston University, 675 Commonwealth Avenue, Boston, MA 02215, USA. (kaufmann@bu.edu; cheryl@bu.edu)

R. B. Myneni, Department of Geography, Boston University, 675 Commonwealth Avenue, Boston, MA 02215, USA. (rmyneni@bu.edu) 